\title{
PROPOSTA PEDAGÓGICA CURRICULAR DO CAMPUS BOA VISTA ZONA OESTE: FORMAÇÃO PROFISSIONAL TÉCNICA E TECNOLÓGICA EM BOA VISTA
}

\section{ARTIGO ORIGINAL}

SILVA, Valério Ramalho da ${ }^{1}$

SILVA, Valério Ramalho da. Proposta pedagógica curricular do Campus Boa Vista Zona Oeste: Formação profissional técnica e tecnológica em Boa Vista. Revista Científica Multidisciplinar Núcleo do Conhecimento. Ano 05, Ed. 12, Vol. 11, pp. 119134. Dezembro de 2020. ISSN: 2448-0959, Link de acesso: https://www.nucleodoconhecimento.com.br/educacao/formacao-profissionaltecnica

\section{RESUMO}

A presente pesquisa discutirá a Proposta Pedagógica Curricular dos Cursos Técnicos Integrados ao Ensino Médio do Campus Boa Vista Zona Oeste - CBVZO/IFRR implantados em 2016, buscando perceber se esta é uma proposta curricular de práticas que favoreçam a diminuição das desigualdades sociais e a inclusão dos indivíduos para uma formação cidadã por meio da educação profissional. A metodologia aplicada pautou-se em estudos bibliográficos, em entrevistas informais com a diretora geral, o diretor de ensino, a pedagoga e a assistente social do Campus, ainda foram realizadas análises dos dados coletados no Sistema Unificado de Administração Pública - SUAP alimentado pela Coordenação de Apoio ao Ensino e Aprendizagem - Codae e projetos de ensino. O referencial teórico tem aporte em Ramos (2014), Brasil, MEC, (2005), PPC (2015). Os dados foram analisados e

1 Especialização em Tecnologias em Ensino a Distância. (Carga Horária: 550h). Universidade Cidade de São Paulo, UNICID, Brasil.) - Graduação em Educação Artística - Universidade Federal do Amazonas, UFAM, Brasil. 
apontaram que a proposta pedagógica curricular do Campus Boa Vista Zona Oeste, é potencializada por vários projetos educativos integrados que foram desenvolvidos e possibilitaram uma formação cidadã, cuja concepção pedagógica e produção do conhecimento, seja relacionado também em entender o trabalho enquanto princípio educativo. Em razão disso, o Campus, primou por desenvolver atividades, programas e projetos que envolvessem os estudantes no universo técnico e tecnológico e ainda fortaleceu a permanência destes com êxito, resultando em diversas aprovações dos egressos em concursos públicos e vestibulares.

Palavras-chave: Proposta pedagógica, formação profissional, cidadania.

\section{INTRODUÇÃO}

O presente estudo discutirá a Proposta Pedagógica Curricular Técnicos Integrados ao Ensino Médio do Campus Boa Vista Zona Oeste - CBVZO/IFRR de 2016, buscando perceber se esta é uma proposta curricular de ações que favoreçam a diminuição das desigualdades sociais e a inclusão dos indivíduos para uma formação cidadã por meio da educação profissional.

O Campus CBVZO que pertence ao Instituto Federal de Educação, Ciência e Tecnologia de Roraima - IFRR, concretizou a missão da rede federal de ensino em promover políticas públicas voltadas a sua ampliação, promovendo assim, a implantação e consolidação deste campus na cidade de Boa Vista.

Neste sentido, torna-se importante conhecer as Propostas Pedagógicas Curriculares dos Cursos Técnicos Integrados ao Ensino Médio e as contribuições da PPC, bem como os impactos das políticas públicas na construção de um espaço de inclusão social para a formação integral dos estudantes em uma educação profissional técnica e tecnológica, desde que esse projeto não reduza o processo educativo (educação) às necessidades do mercado de trabalho, reforçando ainda mais o modelo dual de educação como cita Ramos: 
Na primeira metade do século XX a educação profissional foi fortemente marcada pela dualidade de um sistema que se voltava para as elites e outro para as classes populares. A não equivalência entre os cursos secundários e os técnicos, associada aos currículos enciclopédicos dos primeiros, era a expressão concreta de uma distinção social mediada pela educação. Com a industrialização crescente, especialmente a partir de meados desse século, a dualidade foi mantida. (RAMOS, 2014, p.115).

Os cursos apresentados aqui foram implantados em 2016 sendo eles o curso técnico de Serviços Públicos e o curso técnico de Comércio, ambos Integrados ao Ensino Médio.

Esta pesquisa propõe verificar a relevância da Proposta Pedagógica Curricular - PPC desses cursos, a qual, não deverá ser meramente um texto dissociado da realidade dos alunos atendidos. Desse modo, é necessário que esta proposta curricular esteja pautada em uma formação cidadã, cuja concepção pedagógica e produção do conhecimento, seja relacionado também em entender o trabalho enquanto princípio educativo, como mostra Ramos (2014, p. 87), no propósito de "superar a dicotomia trabalho manual / trabalho intelectual, de incorporar a dimensão intelectual ao trabalho produtivo, de formar trabalhadores capazes de atuar como dirigentes e cidadãos". Nesta perspectiva, que contribuição o CBVZO traz em sua Proposta Pedagógica Curricular para a formação profissional na educação técnica e tecnológica?

Em resposta a esta indagação fez-se necessário investigar se a proposta pedagógica curricular do CBVZO aponta por esse caminho, se valoriza uma prática educativa integradora, potencializando conhecimentos que implicam nas relações históricosociais da realidade do estudante, sem perder o foco em uma formação plena e integral.

A metodologia aplicada pautou-se em estudos bibliográficos, em entrevistas informais com a diretora geral, o diretor de ensino, a pedagoga e a assistente social do Campus, ainda foram realizadas análises dos dados coletados no Sistema Unificado de Administração Pública - SUAP alimentado pela Coordenação de Apoio ao Ensino e Aprendizagem - Codae e projetos de ensino.

Disponível em: https://www.nucleodoconhecimento.com.br/educacao/formacao-profissional- 
Esse estudo pretende contribuir para a compreensão do papel do Instituto Federal de Educação, Ciência e Tecnologia de Roraima - IFRR no Estado de Roraima, assim como analisar os impactos de seu papel social quando da oferta de cursos técnicos para os jovens da Zona Oeste de Boa Vista.

\section{POLÍTICAS DO IFRR PARA A EXPANSÃO E IMPLANTAÇÃO DO} CBVZO

Boa Vista é a capital de Roraima, e é um município urbano que apresentou como população estimada pelo Instituto Brasileiro de Geografia e Estatística - IBGE para 2018, cerca de 375.374 habitantes. Nela concentra-se a maior parte da população roraimense, cerca de 65,3\% segundo o último censo realizado em 2010. Este mesmo Censo Demográfico informa que a Zona Oeste é composta por 39 bairros, onde vivem 229.454 pessoas, o que representa $80,3 \%$ do município sendo área mais populosa.

A Zona Oeste de Boa Vista, é a região que mais cresce na capital, portanto, uma área que apresenta grande demanda para cursos a serem oferecidos pelo IFRR / Campus Boa Vista Zona Oeste - CBVZO. A justificativa para essa expansão da rede federal de ensino técnico e tecnológico é referente a grande demanda populacional e ainda a oportunidade do CBVZO garantir o interesse, os anseios e a qualificação da clientela atendida, despertando o interesse para o ensino, a pesquisa e a extensão e, ainda, o prosseguimento vertical dos estudos. (PPC, 2016, p.7)

Desse modo, quando se pensa em educação profissional alicerçadas num ideário de formação humana na sua totalidade seria uma forma de reconstruí-la como política pública e:

corrigir distorções de conceitos e de práticas decorrentes de medidas adotadas pelo governo anterior, que de maneira explícita dissociaram a educação profissional da educação básica, aligeiraram a formação técnica em módulos dissociados e estanques, dando um cunho de treinamento superficial à formação profissional e tecnológica de jovens e adultos trabalhadores (BRASIL, MEC, 2005, p. 2). 
Nesse sentido, de acordo com o Plano de Desenvolvimento Institucional -PDI do IFRR, por exemplo, observa-se que "entre as atividades econômicas que compõem a economia local, a Administração Pública é responsável por $49,7 \%$ do Produto Interno Bruto (PIB) total; o Comércio, por 12,0\%; e a Construção Civil, por 9,5\%." Nessa perspectiva, justificou-se a implantação dos Cursos Técnicos em questão, ao se perceber que os profissionais técnicos formados atenderão uma demanda crescente em Roraima, tendo em vista que o setor do Comércio representa a segunda maior atividade econômica no Estado e há uma grande demanda na formação de profissionais em Serviços Públicos, para atuar em instituições públicas do país.

A partir do levantamento de interesse da sociedade local, também realizado por meio de audiências públicas, por cursos profissionalizantes no contexto em que o Campus Boa Vista Zona Oeste está inserido, verificou-se que havia demanda específica para o Curso Técnico em Comércio e Serviços Públicos. Assim, em suas propostas pedagógicas curriculares são apresentados como objetivos gerais de formação para Serviços Públicos

Formar profissionais especialmente para o setor público, especializandose em funções de gestão intermediária no atendimento, no apoio administrativo e no controle dos procedimentos organizacionais, para que possam atender os processos produtivos de forma adequada à atividade pública, bem como desenvolver no educando a formação social, cultural, humanística e integral, para o desenvolvimento de cidadãos críticos e reflexivos capazes de compreender e atuar na sua realidade. (PPC SP, 2015, p. 9)

E para o Comércio

Formar profissionais com habilidades e competências para atender as demandas do segmento do Comércio, com capacidades para o exercício da cidadania e a preparação para o mundo do trabalho, incluindo formação ética, social, cultural, humanística e integral, bem como o desenvolvimento da autonomia intelectual e do pensamento crítico (PPC COMÉRCIO, 2015, p. 9)

São apresentados no documento as orientações e conduções para o processo formativo do aluno que serão melhor explicitados abaixo.

Disponível em: https://www.nucleodoconhecimento.com.br/educacao/formacao-profissional- 


\subsection{PERSPECTIVAS PARA O PRIMEIRO MOMENTO DA IMPLANTAÇÃO}

À frente da urgência em promover ações que efetivassem as políticas de expansão, foram iniciadas algumas metas:

- A forma de ingressos para os cursos regulares foi através de processo seletivo;

- Implantou-se atividades de extensão, com cursos aberto a comunidade;

- Atividades esportivas e artísticos culturais;

- Cursos do PRONATEC;

- Parceria com as Escolas do entorno para capacitação dos docentes e técnicos administrativos;

- Políticas públicas para assistência ao educando.

Neste primeiro momento, devido a obra do prédio ainda estar em fase de conclusão, - Campus Boa Vista Zona Oeste funcionou com sede provisória na Escola Estadual Elza Breves de Carvalho, no período de 2014 até aos meados do $1^{\circ}$ semestre de 2016. Neste período o Campus promoveu a formação 107 alunos no curso de especialização Educação a Distância Proeja - (Programa Nacional de Integração da Educação Profissional com a Educação Básica na Modalidade de Educação de Jovens e Adultos), uma forma de capacitar professores para atuar nesta modalidade de ensino, dados levantados pela Coordenação de Registro Escolar - CORES, atuou com Projeto de Extensão: Pré-ENEM, Eureka e PRONATEC com 09 turmas totalizando 225 alunos.

Em 2014.2 até 2015, o Campus começou a trabalhar sua proposta pedagógica curricular com as turmas dos Cursos Técnicos em Serviços Públicos (Subsequente) e Comércio (Subsequente). No sentido de melhorar o êxito, qualidade e permanência dos estudantes, foram adotadas algumas políticas públicas de assistência a esses alunos, como auxílio transporte, material didático, projeto de extensão, projeto de pesquisa. Dentre esses o Programa Institucional Clube da Ciência - PICC, Programa 
Institucional de Bolsas de Iniciação Científica e Tecnológica - PIBICT e Programa Institucional de Apoio à Pesquisa Aplicada/Docente - PIPAD para professores.

Para atender uma grande demanda social, em 2016 foram implementados dois Cursos Técnicos Integrados ao Ensino Médio. Contudo, devido ao pouco espaço na escola estadual, os cursos técnicos integrados ao ensino médio foram remanejados para o Campus Boa Vista, no bairro Pricumã, funcionando neste espaço até o final de 2017.

Somente no início do ano letivo de 2018 os alunos dos cursos técnicos passaram a estudar no CBVZO, por ter sido entregue sua primeira etapa, chegando a $93 \%$ da obra concluída. A instituição possui um terreno de $50.000 \mathrm{~m}^{2}$ (doação da Prefeitura Municipal de Boa Vista (PMBV), já escriturado); no Bloco 1: estão os setores administrativos, Direção Geral, Cores, Codae; já no Bloco 2: salas de aulas, laboratórios didáticos; biblioteca, sala de professores e das coordenações funcionando provisoriamente.

Desse modo, quando se pensa em um curso técnico tecnológico através de uma proposta curricular, que valorize os arranjos produtivos desta imensa zona urbana, faz-se necessário que ações como essas sejam efetivadas em benefício deste cidadão brasileiro, possibilitando assim, promover a formação de indivíduos conscientes e críticos para construir o desenvolvimento social que desejamos. Sobre esse desejo de construir um currículo que reconheça as necessidades do lugar Ramos contribui:

Afirmamos que os processos de produção, ao mesmo tempo em que são partes de uma realidade econômica, social, ambiental, histórica, política e cultural mais ampla, só podem ser compreendidos como particularidade, mas em relação a essa totalidade se, ao mesmo tempo, vamos às mediações específicas que o constituem e que os relacionam com a realidade concreta mais ampla. Por isso, uma indicação é que se elaborem os currículos mediante o estudo de problemas de uma área profissional em múltiplas dimensões, tais como econômica, social, política, cultural e técnica. Os conceitos "pontos-de-partida" para esse estudo revertem-se em conteúdos de ensino sistematizados nas

Disponível em: https://www.nucleodoconhecimento.com.br/educacao/formacao-profissionaltecnica 
diferentes áreas de conhecimento e suas disciplinas (RAMOS, 2014, p. 98).

\section{CONTEXTO HISTÓRICO-SOCIAL, GEOGRÁFICO E ECONÔMICO DO ENTORNO DO CBVZO}

Com a Lei Federal o 11.892, foram criados, no Brasil, os Institutos Federais de Educação, Ciência e Tecnologia, em 29 de dezembro de 2008, esta mesma lei institui a criação, do Instituto Federal de Educação, Ciência e Tecnologia de Roraima - IFRR. A partir da sinalização do Governo Federal, através da autorizado via Portaria MEC no 993/2013 de 07 de outubro de 2013, inicia-se o processo de implantação do Campus Boa Vista Zona Oeste/IFRR.

Em 2014, atendendo a política expansionista da rede federal, o Campus Boa Vista Zona Oeste passa a funcionar enquanto sede provisória na Escola Estadual Elza Breves de Carvalho, para atender uma demanda expressiva de jovens e adultos, tendo em vista que a região em questão apresenta um volume populacional elevado e uma forte inclinação para os Arranjos Produtivos Sociais e Culturais Locais (APSCL).

Com o objetivo de ressaltar a importância desse processo de implantação do CBVZO, iremos contextualizar através dos aspectos histórico-sociais, geográficos e econômicos, as etapas da fundação e consolidação de mais um campus, enquanto projeto de inclusão social, através da educação profissional, técnica e tecnológica.

Neste sentido, ao propor a implantação do Campus Boa Vista Zona Oeste, o IFRR, por meio de sua gestão, visou responder a uma demanda social, promovendo a inserção deste público através da formação profissional e tecnológica, e assim, oferecendo dois eixos formativos na área de gestão, cursos técnicos na modalidade subsequente e integrado ao ensino médio em comércio e serviços públicos.

Quando se fala em formação integrada, trata-se em desconstruir o entendimento que este tipo de formação é somente para dos indivíduos no que concerne ao aspecto 
operacional, desvinculado dos conhecimentos técnicos, tecnológicos e científicos, como destaca Ramos:

A ideia de formação integrada sugere superar o ser humano dividido historicamente pela divisão social do trabalho entre a ação de executar e a ação de pensar, dirigir ou planejar. Trata-se de superar a redução da preparação para o trabalho ao seu aspecto operacional, simplificado, escoimado dos conhecimentos que estão na sua gênese científicotecnológica e na sua apropriação histórico-social (RAMOS, 2014, p. 86).

Desse modo, quando se propõem dar uma resposta a sociedade através de políticas públicas no âmbito educacional, esta deve estar alicerçada em uma concepção de educação integral, procurando superar a dicotomia entre trabalho manual e intelectual.

Para conhecermos o público alvo dessas políticas, vamos analisar um pouco do perfil socioeconômico, por meio de uma pesquisa desenvolvida pela equipe da Coordenação de Apoio ao Ensino e Aprendizagem - CODAE/CBVZO, que demonstra através dos dados estatísticos o perfil desses jovens e adultos situados neste espaço geográfico que é a zona oeste de Boa Vista.

Por intermédio dos gráficos 1 e 2, apresentaremos o nível de escolaridade dos pais desses estudantes. 
Gráfico1 e 2 - Nível de escolaridade dos pais dos estudantes do CBVZO/IFRR
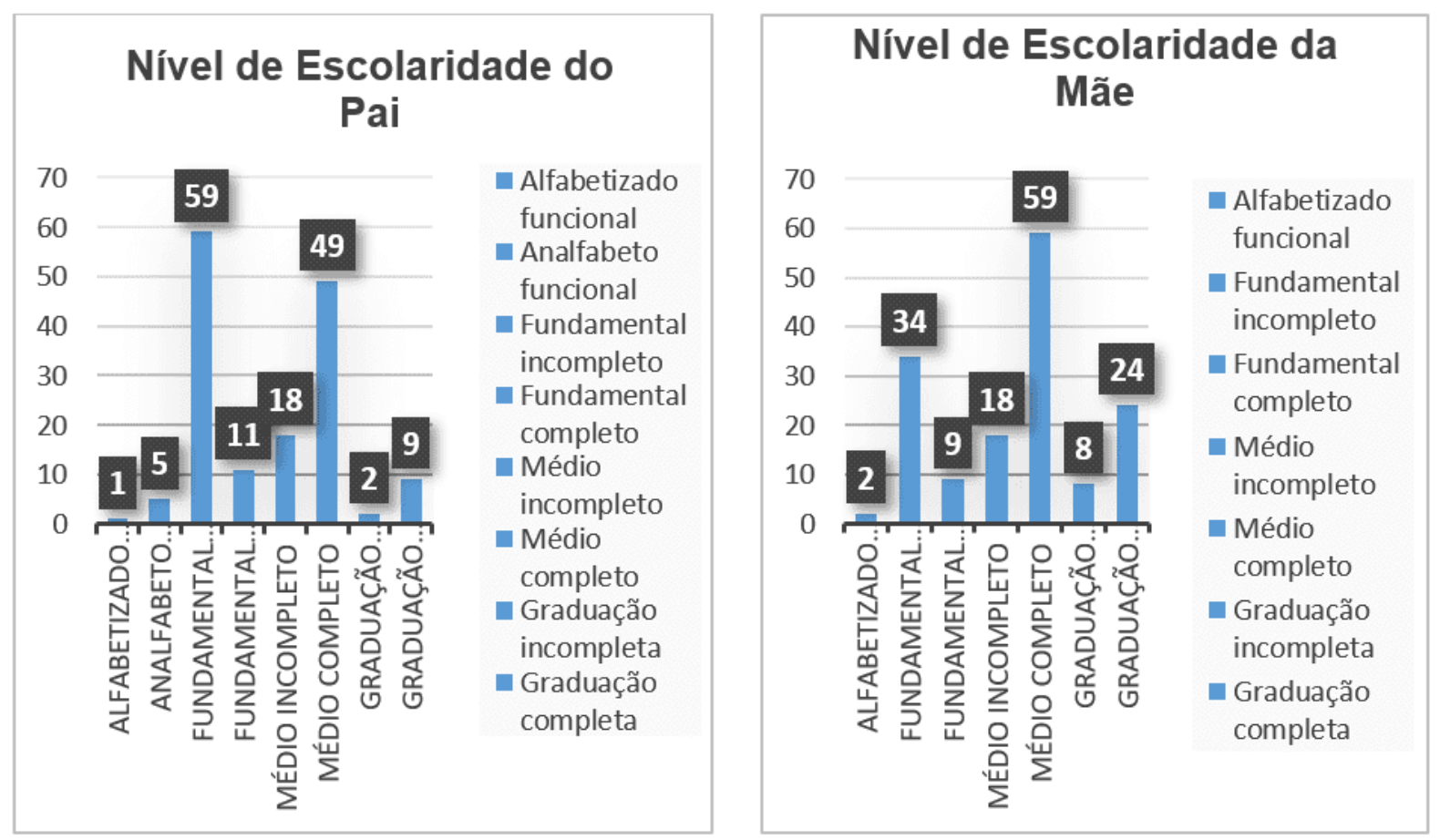

Fonte: Pesquisa realizada pela CODAE (2016)

Observou-se nestes gráficos que em relação a escolaridade a mãe possui uma melhor formação em relação ao pai, tendo a maioria, o ensino médio completo. $O$ pai apresenta como maior nível de escolaridade o ensino fundamental incompleto. 
Gráfico 3 e 4: Renda Bruta Familiar e Per Capita das famílias dos estudantes do CBVZO

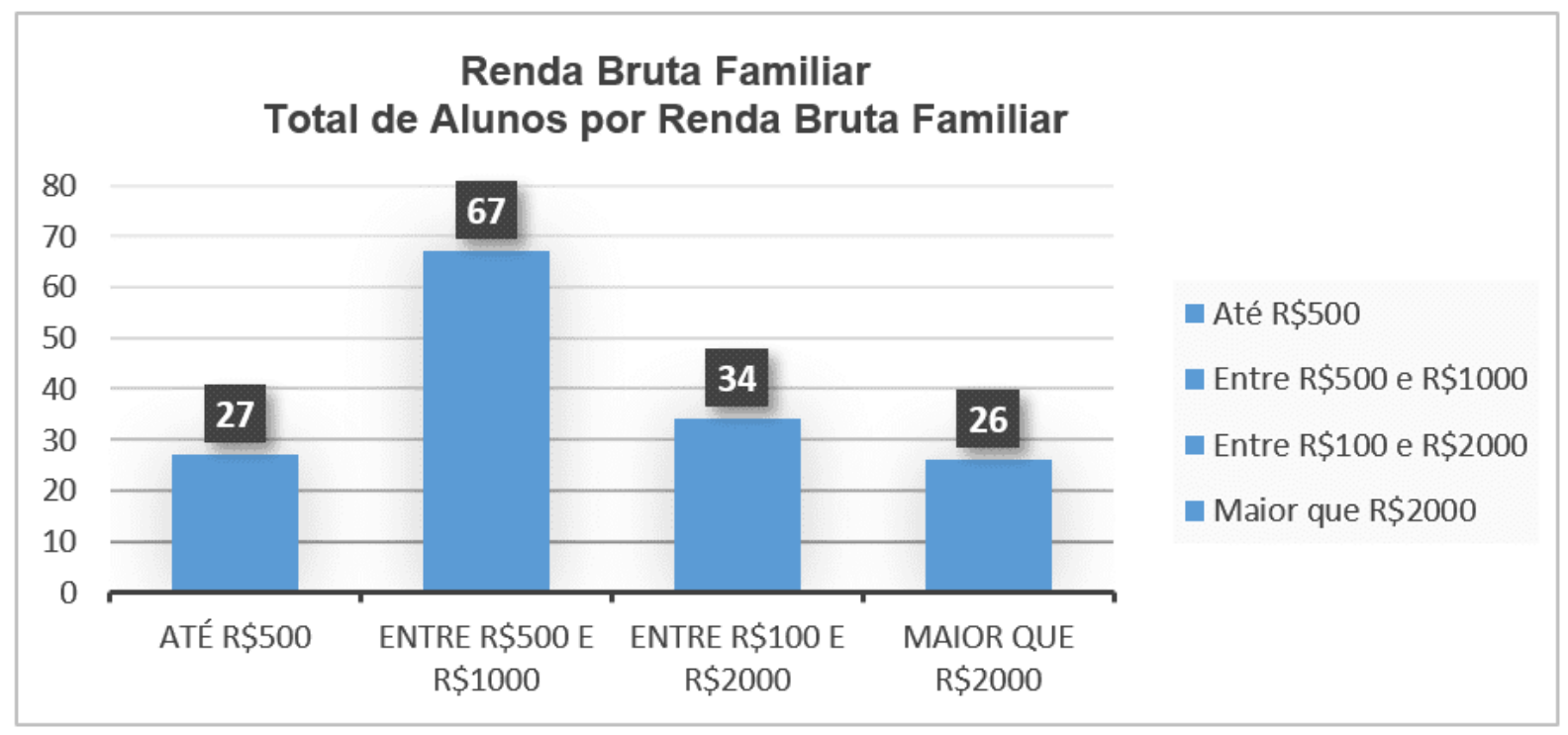

Fonte: Pesquisa realizada pela CODAE (2016)

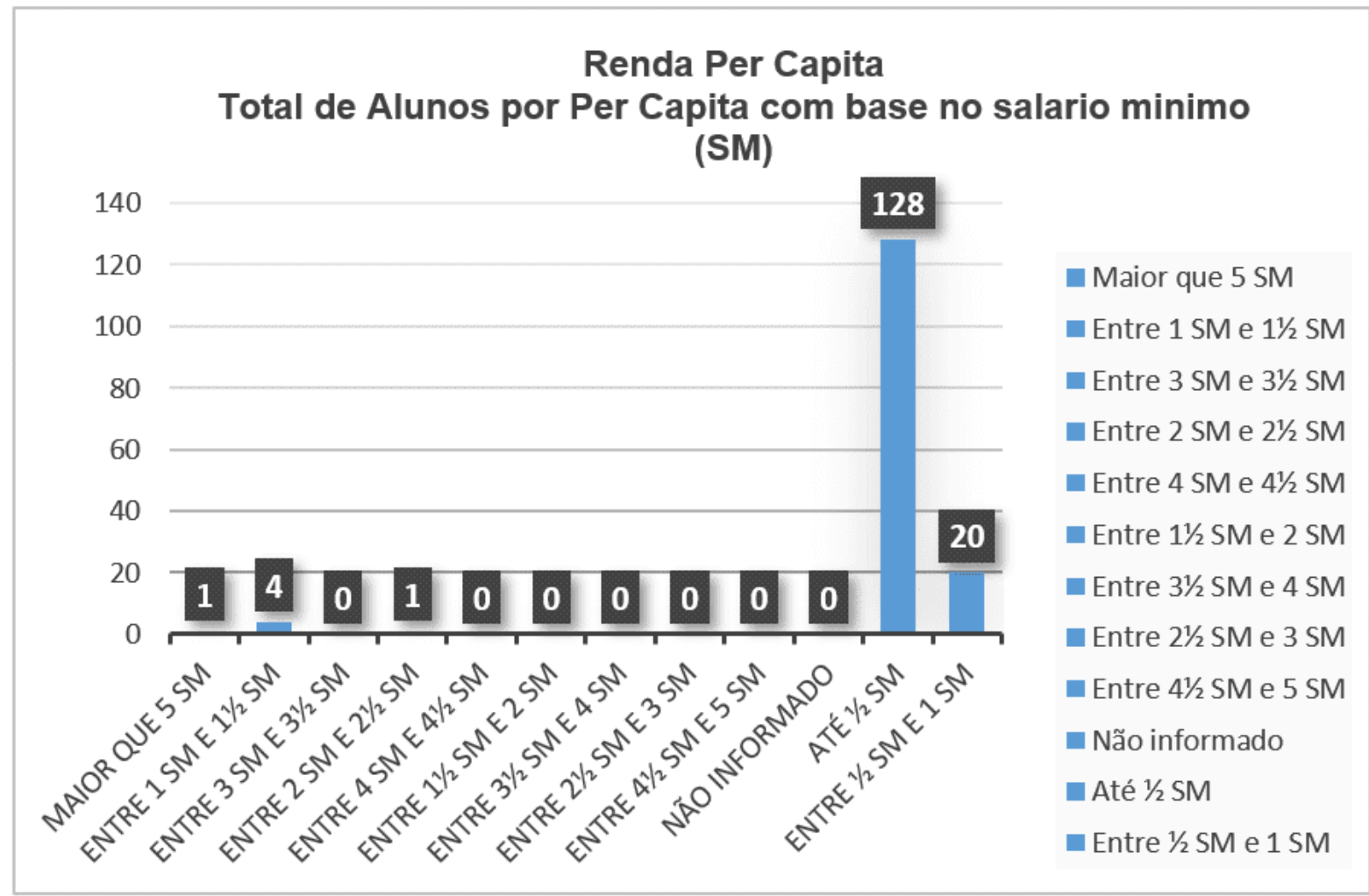

Fonte: Pesquisa realizada pela CODAE (2016)

$\mathrm{RC}: 70462$

Disponível em: https://www.nucleodoconhecimento.com.br/educacao/formacao-profissionaltecnica 
Estes gráficos estatísticos mapeiam que boa parte dessas famílias tem uma renda de subsistência entre salários mínimos, por isso, a necessidade de políticas públicas, não somente na área educacional, como também nas demais.

Gráfico 5: Zona residencial dos estudantes do CBVZO/IFRR

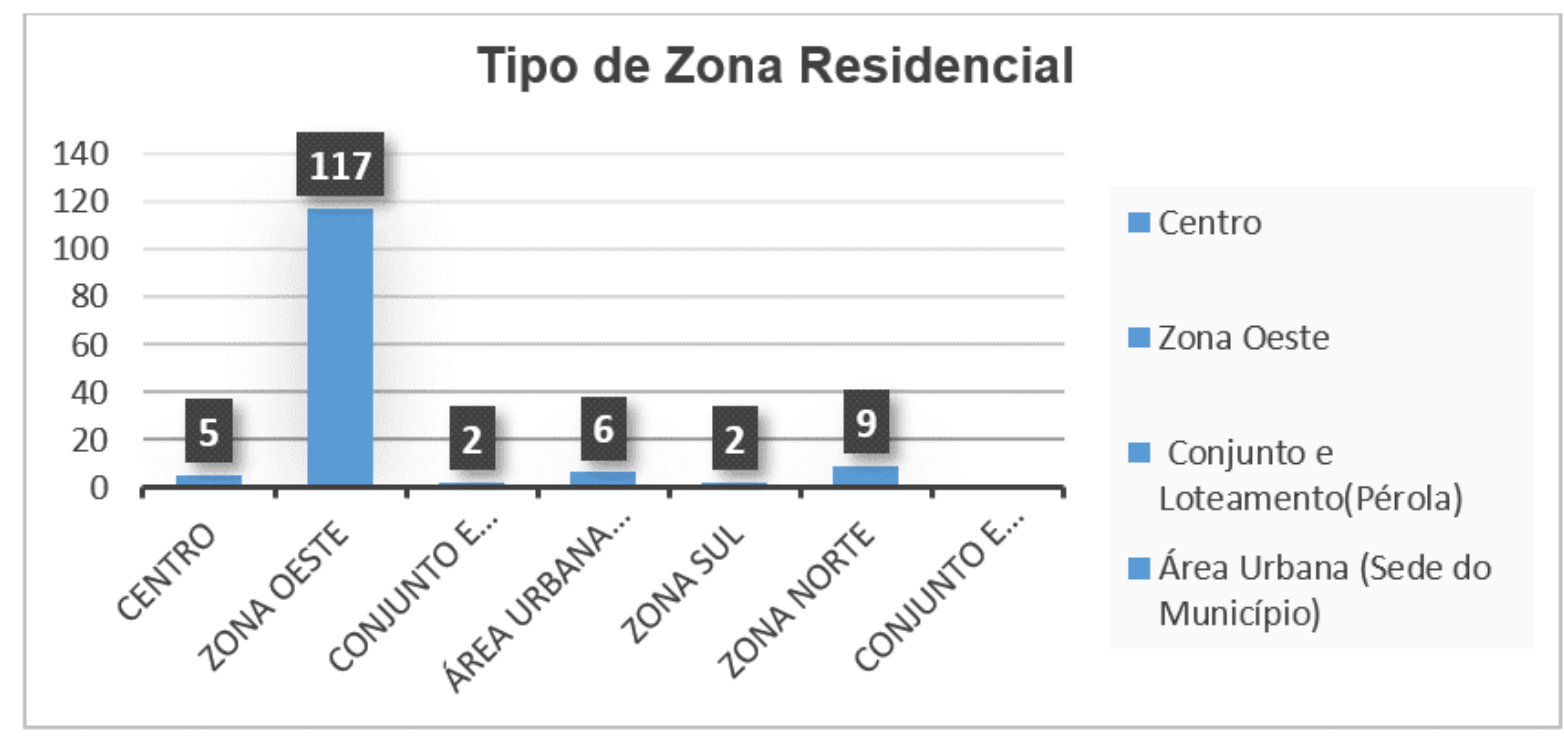

Fonte: Pesquisa realizada pela CODAE (2016)

Ficou evidenciado que cerca de $83 \%$ dos estudantes do Campus Boa Vista Zona Oeste/IFRR, habitam nesta área da cidade.

Por isso, quando se pensa na construção de um projeto pedagógico de cursos técnicos, não é reduzir a educação profissional visando somente a inserção dos jovens e adultos ao mundo do trabalho, é algo que vai além, devendo assim, articular as exigências econômicas e sociais, campo onde esses sujeitos produzem seus saberes e sustento diário.

\section{RESULTADOS/DISCUSSÕES}

A educação escolar em toda sua história traz profundas discussões sobre suas intenções e impactos na vida dos alunos e na sociedade. Implantar um novo campus de formação profissional para jovens em um município, de um estado no extremo norte 
do país também compõem diversas discussões para a dimensão dos impactos que isso traz para a região, o município e o cidadão estudante. Neste sentido, Jaqueline Moll afirma:

Isso implica retirar o foco do projeto educacional do mercado de trabalho, seja ele estável, e colocá-lo sobre os sujeitos. Não sujeitos abstratos e isolados, mas sujeitos singulares cujo projeto de vida se constrói pelas múltiplas relações sociais, na perspectiva da emancipação humana, que só pode ocorrer à medida que os projetos individuais entram em coerência com um projeto social coletivamente construído (MOLL, 2010, p.48).

A interpretação da realidade local com suas necessidades, para o crescimento e desenvolvimento humano é fator precípuo para construção de uma sociedade livre, justa e solidária, e que garanta o desenvolvimento nacional.

A escolha da zona oeste do município de Boa Vista, cumpre a função social quando propõem atender a área mais populosa da capital de Roraima, totalizando uma população de 229.454 pessoas, o que representa $80,3 \%$ desses habitantes, conforme estimativa do IBGE para 2017. Esta é caracterizada por trabalhadores descendentes de índios e migrantes de diversas regiões do país, principalmente Norte e Nordeste. Estes indivíduos apresentam geralmente baixa escolaridade e pouca qualificação profissional, sobrevivendo dos programas do governo federal, mercado de trabalho informal sem garantias trabalhistas.

Pelos gráficos apresentados percebe-se que as famílias dos alunos do CBVZO são oriundas dessas regiões e com características de vida e sobrevivência com muitas dificuldades.

Ficou evidenciado que cerca de $83 \%$ dos estudantes do Campus Boa Vista Zona Oeste/IFRR, habitam nesta grande área da cidade, desse modo, justifica-se a implantação desta instituição de ensino, cumprindo assim, seu papel social econômico e político. 
Neste sentido, após compreendermos a proposta de formação prevista na Proposta Pedagógica Curricular dos Cursos Técnicos Integrados ao Ensino Médio do Campus Boa Vista Zona Oeste - CBVZO/IFRR de 2016, e em seu projetos educativos verificouse no PPC que algumas ações como: Prática Profissional Integrada, Estágio Curricular / Trabalho de Conclusão de Curso (Projeto de Intervenção), Atividades Complementares, Acompanhamento de Egressos e Assistência Estudantil, foram potencializadas por meio de projetos integradores e intervenção na prática do estágio curricular, afim de contribuir para a compreensão e aplicação dos conceitos e conteúdos próprios dos componentes curriculares, inseridos na realidade destes estudantes.

Considerando o que foi exposto, mas sem aprofundar a respeito dos projetos que foram desenvolvidos na formação desses estudantes, citaremos os projetos que corrobora com a proposta deste projeto pedagógico curricular do Campus em questão.

1- Projeto Integrado: Cliente Oculto, como o outro vê, cuja a justificativa era promover o conhecimento de conteúdos relacionados entre as disciplinas da área profissional e integração entre os alunos dos cursos Técnico em Comércio e Técnico em Serviços Públicos, mesmo que a área fim seja diferente, ambos lidam com aspectos de atendimento, vendas de produtos e/ou serviços e qualidade nos serviços prestados.

\section{2- O projeto "Mitos Gregos: Arte, Filosofia e História na Grécia Antiga" visou} promover semanalmente um diálogo entre discentes, docentes e comunidade escolar tendo como elemento norteador os mitos gregos. Valendo-se de atividades e linguagens artísticas diversas: artes cênicas, artes plásticas, música, cinema, saraus literários, buscou-se desenvolver aprendizagens historiográficas e filosóficas concernentes à Grécia Antiga.

3- Os Projetos Pedagógicos dos Cursos Técnicos Integrado ao Ensino Médio do IFRR/ Campus Boa Vista Zona Oeste contemplaram em sua organização curricular a oferta do programa de Nivelamento Escolar para o desenvolvimento de conhecimentos 
elementares, envolvendo prioritariamente os conteúdos de Língua Portuguesa e Matemática.

5- "Conhecer é o melhor remédio", que teve como objetivo, fornecer informação e esclarecimento sobre temas relacionados às ISTs, (Infecções Sexualmente Transmissíveis) em especial a AIDS (Síndrome da Imunodeficiência Adquirida), assim como sexualidade, orientação sexual e identidade de gênero.

6- Projeto de Ensino: Esporte, Educação e Cidadania, cujo objetivo era possibilitar, por meio da prática de atividades de Educação Física, melhoria no processo de ensino aprendizagem dos estudantes e de autoafirmação como cidadão protagonista de suas escolhas, a partir da melhoria das relações interpessoal, em grupo, com o IFRRCBVZO e com as demais pessoas envolvidas no cotidiano desses estudantes.

7- Projeto de Recreação Escolar: Objetivo foi promover ações de integração, de convivência e de descanso que motivassem os estudantes dos Cursos Técnicos Integrados ao Ensino Médio do IFRR/ Campus Boa Vista Zona Oeste, a permanecer e obter êxito durante o seu percurso formativo.

8- Projeto Arte e Cultura do Campus Boa Vista Zona Oeste: O objetivo era proporcionar ações educativas e complementares que envolvessem estudantes dos diferentes cursos técnicos em atividades de vivência, fruição, leitura e construção poética ligadas às diferentes linguagens da arte (Dança, Cinema, Música, Literatura, Teatro, Artes Visuais e Audiovisuais), promovendo a vivência artística e estética dos estudantes e comunidade do Campus e oportunizando o conhecimento em Arte nos seus diferentes desdobramentos.

9- Roraima, estudos para compreensão da sua diversidade natural e humana: $\mathrm{O}$ objetivo foi proporcionar aos alunos um amplo conhecimento acerca do estado de Roraima, considerando sua diversidade natural e humana.

Fica evidenciado que toda proposta pedagógica necessita que suas práticas enquanto eixos formativos, ganhem potência por meio de projetos integradores, possibilitando

Disponível em: https://www.nucleodoconhecimento.com.br/educacao/formacao-profissional$\underline{\text { tecnica }}$ 
assim, uma proposta curricular de ações que favoreçam a diminuição das desigualdades sociais e a inclusão dos indivíduos para uma formação cidadã por meio da educação profissional.

Outro ponto a considerar são os objetivos gerais para a formação técnica dos educandos, tanto do setor público e do comércio disposto nos dois planos, propondo ao educando o desenvolvimento para uma formação social, cultural, humanística e integral, com vistas e uma formação crítica com cidadãos atuantes na sociedade.

E finalmente o resultado de pós formação que pôde ser comprovado em recente publicação sobre os alunos, hoje egressos, aprovados em concursos e/ou vestibulares do estado. De acordo com, a fonte de pesquisa, http://www.ifrr.edu.br/campi/zonaoeste/noticias/egressos.

Em 2018 o CBVZO formou 103 alunos, sendo 69 egressos do técnico em serviços públicos e 34 egressos do curso técnico em Comércio. Dos 103 alunos egressos, 46 ou (45\%) passaram em vestibulares, destes 34 passaram em vestibulares de Instituições de Ensino Superior Pública (UFRR, UERR, IFRR). Dos 103, 02 passaram em concurso público da prefeitura no cargo de assistente/cuidador de aluno, nível médio. Dos 103 ex-alunos, 08 estão atuando na área de comércio como representante ou promotor de vendar. Dos 103, 05 estão atuando como empreendedores, no que é classificado como empreendedorismo por necessidade.

O Campus apesar das dificuldades quanto ao seu espaço e prédio, primou por desenvolver atividades, programas e projetos que envolvessem os estudantes no universo técnico e tecnológico e ainda fortalecendo a permanência destes com êxito, no qual resultou em diversas aprovações dos egressos em concursos públicos e vestibulares.

\section{CONSIDERAÇÕES FINAIS}

Objetivamos neste trabalho compreender o papel do Instituto Federal de Educação, Ciência e Tecnologia de Roraima no Estado de Roraima, bem como analisar e 
descrever os impactos de seu papel social, quando da oferta de cursos técnicos para os jovens da Zona Oeste de Boa Vista, através do campus CBVZO.

Neste sentido, podemos afirmar que a educação profissional ofertada em nível médio aos jovens do município de Boa Vista mostra-se como uma oportunidade de progressão social e econômica, viabilizando para estes a verticalização de seus estudos quando da aprovação de muitos desses para cursos superiores e ainda a entrada no mercado de trabalho que atualmente faz exigências de formação global para o jovem trabalhador.

Percebe-se ainda que a proposta pedagógica se consolida como agente formador para a cidadania quando abre espaço para outras práticas pedagógicas formativas como os projetos integrados. Estes impulsionam os discentes a perceberem além dos conteúdos programáticos técnico e propedêutico postos no PPC a importância de sua formação para o exercício da cidadania e à preparação para o trabalho com forte base ética, valorização do desenvolvimento da autonomia intelectual e do pensamento crítico.

No entanto precisa-se considerar que as diferentes mudanças de local de funcionamento (campus) do curso trazem dificuldades tanto para o corpo técnico/pedagógico, docente, como para o discente. São novas adaptações para superar as rupturas de programas e ações planejadas. Trazendo desafios de readaptação e replanejamento para o contínuo trabalho programático e formativo dos alunos.

São reflexões sobre os desafios da educação profissional que trazemos que também poderão contribuir para novas discussões acerca do assunto.

\section{REFERÊNCIAS BIBLIOGRÁFICAS}

BRASIL. Conselho Nacional de Educação (CNE). Parecer n. 16, de 5 de outubro de 1999. Diretrizes Curriculares Nacionais para a Educação Profissional de Nível Técnico.

Disponível em: https://www.nucleodoconhecimento.com.br/educacao/formacao-profissionaltecnica 
. Conselho Nacional de Educação (CNE). Parecer n. 39, de 8 de dezembro de 2004. Aplicação do Decreto n. 5.154/2004 na Educação Profissional Técnica de nível médio e no Ensino Médio.

- Conselho Nacional de Educação (CNE). Resolução CNE/CEB n. 01/04.Institui as Diretrizes para a organização e a realização de Estágio de discente da Educação Profissional e do Ensino Médio inclusive na modalidade de Educação Especial.

. Conselho Nacional de Educação (CNE). Resolução CNE/CEB n. 04/05. Inclui novo dispositivo à Resolução CNE/CEB №. 01/05, que atualiza as Diretrizes Curriculares Nacionais definidas para o Ensino Médio e para a Ed. Profissional Técnica de nível médio às disposições do Decreto no 5154/04.

. Conselho Nacional de Educação (CNE). Resolução CNE/CEB n. 02/05. Modifica a redação do $\S^{\circ}{ }^{\circ}$ do art. $5^{\circ}$ da Resolução CNE/CEB N 1/2004.

. Conselho Nacional de Educação (CNE). Resolução n. 4, de 8 de dezembro de 1999. Institui as Diretrizes Curriculares Nacionais para a Educação Profissional nível técnico . Instituto Brasileiro de Geografia e Estatística - IBGE. Roraima. Contagem da População 2010. Disponível em http:Ilcenso2010.ibge.gov.brlappslatlas. Acesso em: 20 de maio de 2019.

. INSTITUTO FEDERAL DE EDUCAÇÃO, CIÊNCIA E TECNOLOGIA DE RORAIMA/CAMPUS BOA VISTA ZONA OESTE. Disponível em http://www.ifrr.edu.br/campi/zona-oeste/noticias/verticalizacao-2013-egressos-dozona-oeste-optam-por-continuar-estudos-no-ifrr Acesso em: 12 de junho de 2019.

. INSTITUTO FEDERAL DE EDUCAÇÃO, CIÊNCIA E TECNOLOGIA DE RORAIMA/CAMPUS BOA VISTA ZONA OESTE. Disponível em http://www.ifrr.edu.br/campi/zona-oeste/noticias/campus-boa-vista-zona-oeste- 
egressos-do-ifrr-conseguem-aprovacao-em-concursos-e-vestibulares Acesso em: 10 de junho de 2019.

. INSTITUTO FEDERAL DE EDUCAÇÃO, CIÊNCIA E TECNOLOGIA DE RORAIMA/CAMPUS BOA VISTA ZONA OESTE. Disponível em http://www.ifrr.edu.br/campi/zona-oeste/noticias/egressos-do-cbvzo-apostam-emgerir-o-proprio-negocio Acesso em: 10 de junho de 2019.

INSTITUTO FEDERAL DE EDUCAÇÃO, CIÊNCIA E TECNOLOGIA DE RORAIMA/CAMPUS BOA VISTA ZONA OESTE Plano Pedagógico do Curso Técnico em Comércio Integrado ao Ensino Médio. Boa Vista, IFRR. 2015.

INSTITUTO FEDERAL DE EDUCAÇÃO, CIÊNCIA E TECNOLOGIA DE RORAIMA/CAMPUS BOA VISTA ZONA OESTE Plano Pedagógico do Curso Técnico em Serviços Públicos Integrado ao Ensino Médio. Boa Vista, IFRR. 2015.

INSTITUTO FEDERAL DE EDUCAÇÃO, CIÊNCIA E TECNOLOGIA DE RORAIMA/CAMPUS BOA VISTA ZONA OESTE - Dados coletados pelo Sistema Unificado de Administração Pública - SUAP, alimentado pela CODAE. Roraima, 2016.

INSTITUTO FEDERAL DE EDUCAÇÃO, CIÊNCIA E TECNOLOGIA DE RORAIMA/CAMPUS BOA VISTA ZONA OESTE - Direção de Ensino - Projetos Integradores. Boa Vista, Roraima, 2018.

INSTITUTO FEDERAL DE EDUCAÇÃO, CIÊNCIA E TECNOLOGIA DE RORAIMA/IFRR - Plano de Desenvolvimento Institucional/PDI. Roraima, 2014.

CHIZZOTTI, Antônio. EPISTEMOLOGIA E CURRÍCULO: "Novos Paradigmas" PUC-SP, Disponível em: http://www.anped.org.br/biblioteca/item/epistemologia-ecurriculo-novos-paradigmas. Acesso em: 02 junho de 2019.

. Ministério da Educação, Portaria № - 994, DE 7 DE OUTUBRO DE 2013

Altera a Portaria MEC no 331, de 24 de abril de 2013, do Ministério da Educação.

Disponível em: https://www.nucleodoconhecimento.com.br/educacao/formacao-profissional- 
. Ministério da Educação. Secretaria de Educação Profissional e Tecnológica. Subsídios para o processo de discussão da proposta de anteprojeto de lei da educação profissional e tecnológica. Disponível em: http://www.mec.gov/setec. Acesso em: 02 maio de 2019.

. Presidência da República. Casa Civil. Lei oㅡ 11.892, de 29/12/ 2008. Institui a Rede Federal de Educação Profissional, Científica e Tecnológica, cria os Institutos Federais de Educação, Ciência e Tecnologia. Brasília/DF: 2008.

MOLL, Jaqueline et. al. Educação profissional e tecnológica no Brasil Contemporâneo: desafios, tensões e possibilidades. Porto Alegre: Artmed, 2010. RAMOS, M.N. História e política da educação profissional. Curitiba: IFPR, 2014. Enviado: Setembro, 2020.

Aprovado: Dezembro, 2020. 